Ciência e Natura, Santa Maria, v. 37 n. 4 set-dez. 2015, p. 198-209

Revista do Centro de Ciências Naturais e Exatas - UFSM

\title{
SIMULAÇÃO DO ESCOAMENTO SUPERFICIAL DE UMA ÁREA PRÉ E PÓS URBANIZAÇÃO
}

\author{
Runoff simulation in a pre and post urbanization area
}

\author{
Mein Mieko Chang, Hemerson Donizete Pinheiro, Deize Dias Lopes
}

Universidade Estadual de Londrina/Centro de Tecnologia e Urbanismo, Londrina, PR, Brasil

\begin{abstract}
Resumo
Este trabalho avaliou, através de simulações, o impacto da urbanização no escoamento superficial na região da Gleba Palhano (Londrina/PR), em que as condições de uso e ocupação do solo mudaram de forma drástica em apenas duas décadas. Foram utilizados modelos hidrológicos para a obtenção dos hietogramas e hidrogramas. Os hietogramas foram gerados a partir dos valores de chuvas intensas e os hidrogramas através do hietograma e da avaliação das condições do solo, anterior à urbanização (1991) e posterior (2013), através do modelo do SCS. As variáveis de entrada foram as condições de uso e ocupação do solo, características e umidade do solo, tempo de retorno e de duração das chuvas. Observou-se que após a urbanização ocorreu o aumento do volume escoado superficialmente na área estudada, uma vez que este é altamente influenciado pelas condições de uso e ocupação do solo. Os resultados da simulação para os dois cenários analisados demonstraram, de forma quantitativa, que o aumento do escoamento superficial foi, respectivamente, para tempos de duração da precipitação de 15minutos, 30minutos, 1hora e 3horas: 139\%, 68\%, 44\% e 35\%, para Tr=2anos, 115\%, 61\%, $41 \%$ e $32 \%$, para $\operatorname{Tr}=5$ anos, $102 \%, 57 \%$, 39\% e 30\%, para $\mathrm{Tr}=10$ anos.
\end{abstract}

Palavras-chave: Drenagem urbana. Escoamento superficial. Impactos da urbanização.

\section{Abstract}

This work intends, through simulations, to rate the urbanization impacts on the runoff at Gleba Palhano zone (Londrina/PR), where the conditions of the land, use and occupation, have changed dramatically in just two decades. Hydrological models were used to obtain the rainfall intensity curves and hydrographs. The rainfall intensity curves were generated from the values of heavy rains and the hydrographs were generated from rainfall intensity curves and by rating the soil conditions, before de urbanization (1991) and after (2013), through SCS model. The input variables were the conditions of the soil, use and occupation, soil humidity and characteristics, turnaround time and duration of the rainfall. Was notice an increase in the runoff volume in the study area after the urbanization, which is highly affected by the soil use and occupation. The simulation results for both sceneries demonstrate an increase of the runoff that was, respectively, for the rainfall duration of 15minutes, 30minutes, 1hour and 3hours: $139 \%, 68 \%, 44 \%$ e $35 \%$, for Tr=2years, 115\%, 61\%, $41 \%$ e $32 \%$, for $\mathrm{Tr}=5$ years, $102 \%, 57 \%$, 39\% e $30 \%$, for $\mathrm{Tr}=10$ years.

Keywords: Urban drainage. Runoff. Urbanization impacts. 


\section{Introdução}

A população urbana da cidade de Londrina, situada no norte do Estado do Paraná, nas últimas decadas, apresentou acelerado ritmo de crescimento. A população urbana saltou de 390.100 no ano de 1991 (PREFEITURA DE LONDRINA, 2014) para uma população estimada de 543.033, em 2014 (IBGE, 2014). Apesar de não haver dados relativos ao crescimento populacional do bairro em estudo, este é expressivo no último valor mencionado devido a expansão habitacional na região. Como na maior parte dos municípios brasileiros, este crescimento ocorreu sem o planejamento adequado. $\mathrm{O}$ desenvolvimento da malha urbana acarretou na rápida alteração do uso e ocupação do solo, influenciando no comportamento hidrológico das bacias envolvidas.

A impermeabilização do solo é uma das principais consequências do inadequado gerenciamento de obras de infraestrutura e da ausência de planejamento urbano que altera a forma como passa a ocorrer o escoamento superficial das águas pluviais. Estas alterações causam o aumento da magnitude e da frequência de inundações (TUCCI, 2009).

Com o desenvolvimento de inúmeros modelos hidrológicos e a utilização de softwares de modelagem, há a possibilidade da criação de diversos cenários e a simulação de eventos hidrológicos para se avaliar as consequências da urbanização no escoamento superficial, além de possibilitar uma análise mais abrangente nos variados campos da gestão e planejamento dos recursos hídricos. Desta forma, medidas de prevenção podem ser tomadas com o intuito de reduzir danos e perdas tanto à população como para o meio ambiente.

Segundo Faria, Barbassa e Silveira (2013), as características da bacia são um dos fatores para a suscetibilidade de enchentes em bacias urbanizadas, onde o parâmetro da porcentagem de área impermeabilizada exerce influências significativas nas ocorrências de inundações. As características das chuvas, como o tempo de retorno e de duração da chuva, são fatores que também provocam tais ocorrências.

Estudos como de Bruno, Amorim e Silveira (2013) demonstram que o tipo de revestimento utilizado em áreas urbanas influencia diretamente no volume que é escoado superficialmente, no qual superfícies cobertas com vegetação tem um potencial de redução da produção de escoamento superficial até 90 vezes maior que o do concreto convencional. Paralelamente ao estudo anterior, Silva et al. (2009) mostraram que as características construtivas, tais como declividade e estado de compactação, e as características relacionadas ao uso dos revestimentos, como colmatação e ação de veículos, podem exercer uma parcela significativa no volume escoado superficialmente em pavimentos permeáveis.

Conforme Reis e Ilha (2014), que realizaram um estudo comparativo de desempenho hidrológico de dois sistemas de infiltração de água de chuva, poços de infiltração e jardins de chuva, mostraram que tais sistemas podem ser integrados às instalações de água pluvial de edificações, possibilitando a redução do volume escoado superficialmente, como também o amortecimento dos picos de vazão do hidrograma.

Pelo exposto anteriormente, este trabalho visa avaliar o impacto da urbanização no escoamento superficial da região nordeste do bairro da Gleba Palhano, através da utilização de modelagem hidrológica. Esta é realizada a partir da simulação de cenários de uso e ocupação do solo, gerando os hidrogramas de escoamento anterior e posterior à urbanização da região, para diferentes tempos de retorno e de duração das chuvas. 


\section{Metodologia}

\section{1 Área de estudo}

O município de Londrina está localizado na região Norte do estado do Paraná, na latitude $23^{\circ} 18^{\prime} 36^{\prime \prime}$ Sul e longitude $51^{\circ} 09^{\prime} 46^{\prime \prime}$ Oeste, conforme ilustra a Figura 1a. A região avaliada foi a região sudoeste da cidade, sendo esta denominada de Bairro Palhano e a área de estudo se encontra a nordeste do referido bairro (Figura 1b).

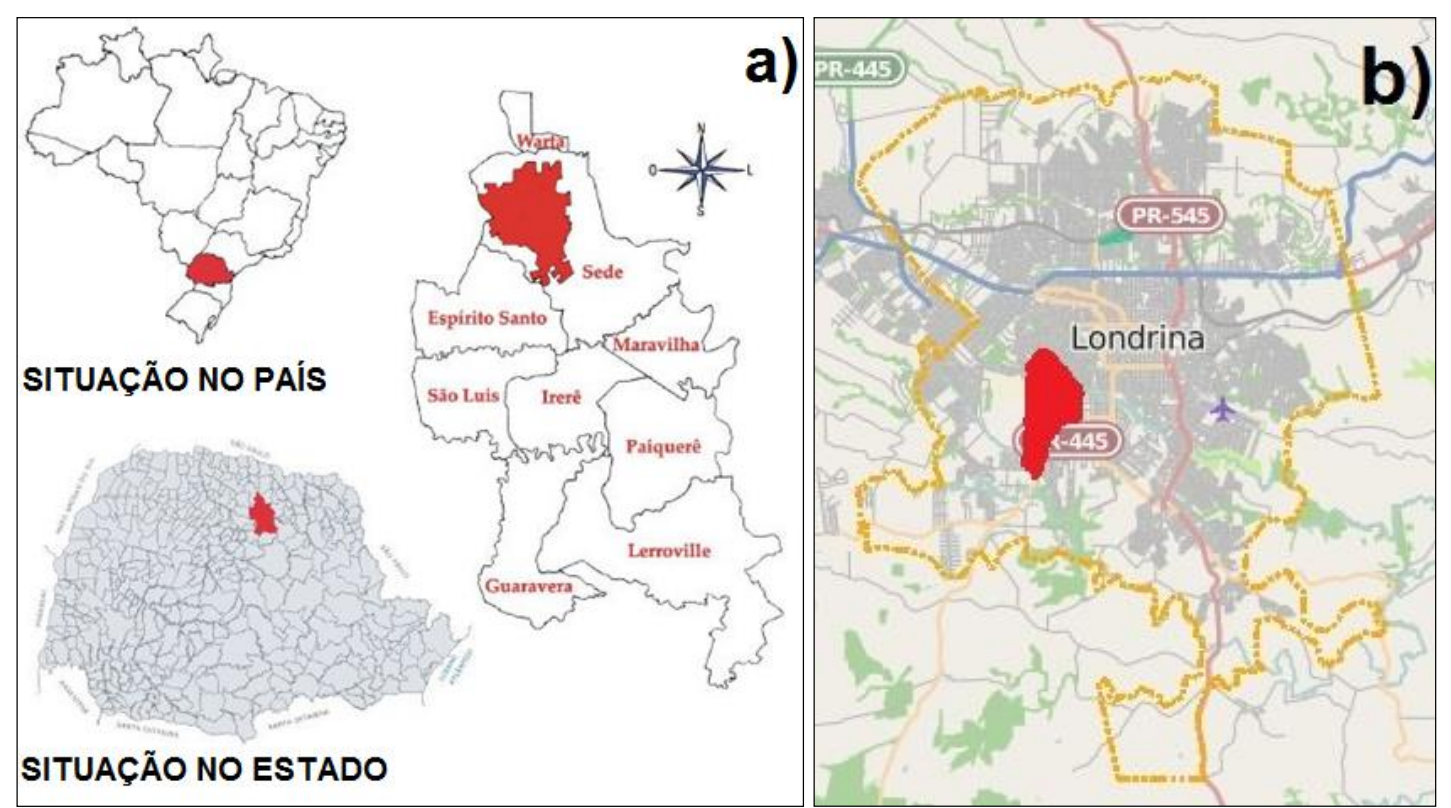

Figura 1: a) Localização da zona urbana no município de Londrina/PR; b) Bairro Palhano em Londrina (PR).

Devido à inexistência de medições de vazões na região, tais vazões foram estimadas através de modelos hidrológicos, no caso o modelo do SCS (Soil Conservation Service), que utilizam certos parâmetros para a conversão da precipitação em vazão. Os parâmetros utilizados foram: características de uso e ocupação do solo, características do solo e condições das chuvas antecedentes.

Os dados referentes às condições físicas da bacia, tais como curvas topográficas e uso e ocupação do solo foram obtidas através de fotos aerofotogramétricas de 1991, imagens atuais do Google Earth e curvas de nível cedidas pela prefeitura do município de Londrina, representada pelo Instituto de Pesquisa e Planejamento Urbano de Londrina (IPPUL).

\subsection{Etapas de desenvolvimento}

Este trabalho foi desenvolvido metodologicamente em quatro etapas principais: 1) definição da área de estudo; 2) definição do hietograma de projeto (ou chuva de projeto); 3) definição dos parâmetros adotados pelo modelo do SCS (Soil Conservation Service); 4) simulação para diferentes cenários. 
Na primeira etapa foi definida a área de estudo, bem como o levantamento de dados da área, tais como área de drenagem, declividade do terreno e extensão do trecho.

$\mathrm{Na}$ segunda etapa foram obtidos os Números de Curva $(\mathrm{CN})$ para as diferentes condições de uso e ocupação do solo (SCS, 1985), em que foram estudadas as condições da área para o ano de 1991, área não urbanizada, utilizada para plantio e ocupada pela vegetação nativa, e de 2013, condição já urbanizada, grande extensão de ruas pavimentadas e lotes ocupados, predominantemente, por condomínios verticais.

Na terceira etapa, foram preestabelecidos os tempos de duração da chuva e o tempo de retorno. Para a obtenção da distribuição temporal das chuvas intensas foi utilizado o método dos Blocos Alternados, cuja intensidade foi obtida através da utilização da Equação de IDF de Fendrich (1998) para a cidade de Londrina, baseada na curva de IDF da cidade com período de observação de onze anos (1975 a 1985), conforme a Equação 1.

$$
\mathrm{i}=\frac{3132,56 \cdot \mathrm{T}_{\mathrm{r}}^{0,093}}{\left(\mathrm{t}_{\mathrm{d}}+30\right)^{0,939}}
$$

Onde a variável i corresponde à intensidade média da chuva máxima $(\mathrm{mm} / \mathrm{h}), \mathrm{T}_{\mathrm{r}}$ ao tempo de retorno (anos); e $t_{d}$ ao tempo de duração da chuva (minutos).

O método dos Blocos Alternados baseia-se na reordenação do hietograma completamente adiantado (pico no início) de forma a reposicionar o pico no centro. Cada "bloco" ou incremento de chuva do hietograma adiantado é sucessiva e alternadamente colocado no entorno do "bloco" de pico, à direita e à esquerda

Finalmente na última etapa, as simulações foram realizadas com diferentes tempos de retorno (2, 5 e 10 anos), duração da chuva (15, 30, 60 e 180 minutos) e para as duas condições de uso e ocupação do solo. Nesta etapa foi avaliado, de forma quantitativa, o aumento do escoamento superficial.

A elaboração das tabelas se deu a partir da utilização de planilhas eletrônicas na plataforma do Microsoft Office Excel. Para que fosse possível a avaliação quantitativa do aumento do escoamento superficial, foi utilizado o modelo do SCS para a transformação da chuva em vazão.

Para fazer as simulações, foram utilizados como dados de entrada da planilha eletrônica: dados físicos da bacia (área, extensão longitudinal da bacia e declividade), número de curva $(\mathrm{CN})$ e os dados de precipitação (tempo de retorno e tempo de duração). Os dados de saída foram apresentados na forma de hietogramas e hidrogramas de escoamento superficial.

\subsection{Dados físicos da bacia e quantificação das áreas}

Fazendo uso das curvas de nível e das fotos aerofotogramétricas, estas foram sobrepostas na plataforma do programa AutoCAD, e assim foram adquiridas as metragens quadradas e as porcentagens referentes à área construída de edificações e arruamento, terrenos baldios, plantações, entre outros para os anos de 1991 e 2013. Nas Figuras 2 e 3 são apresentadas as sobreposições dos mapas dos referidos anos de análise. 


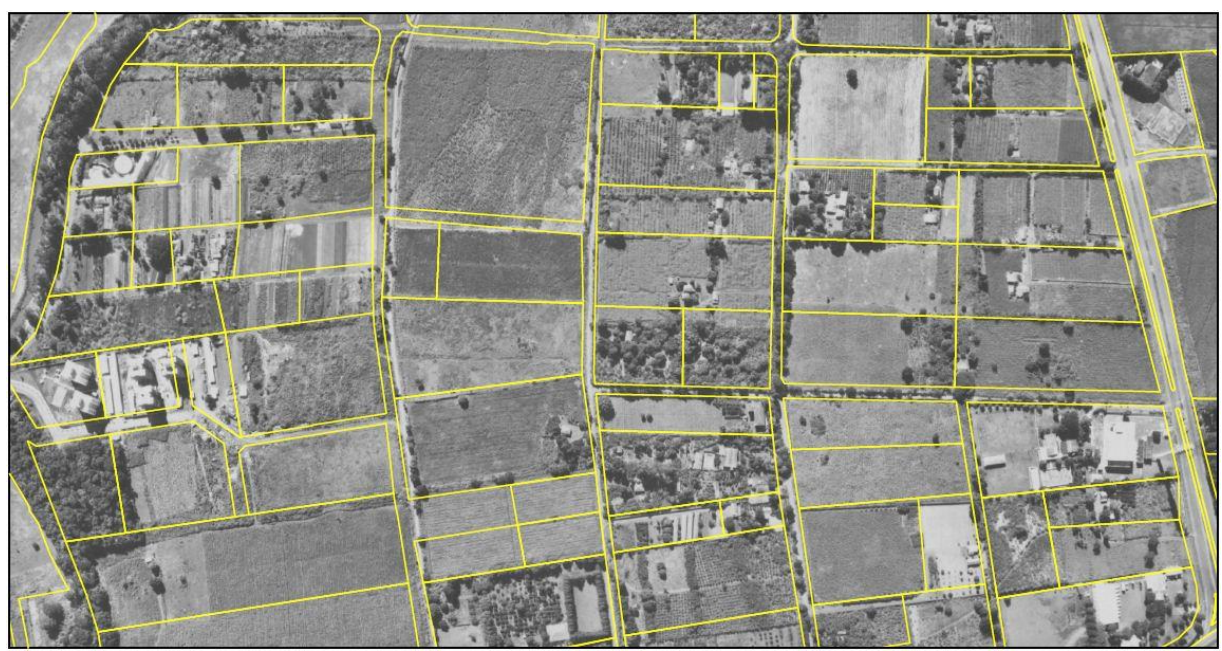

Figura 2: Sobreposição de imagens 1991.

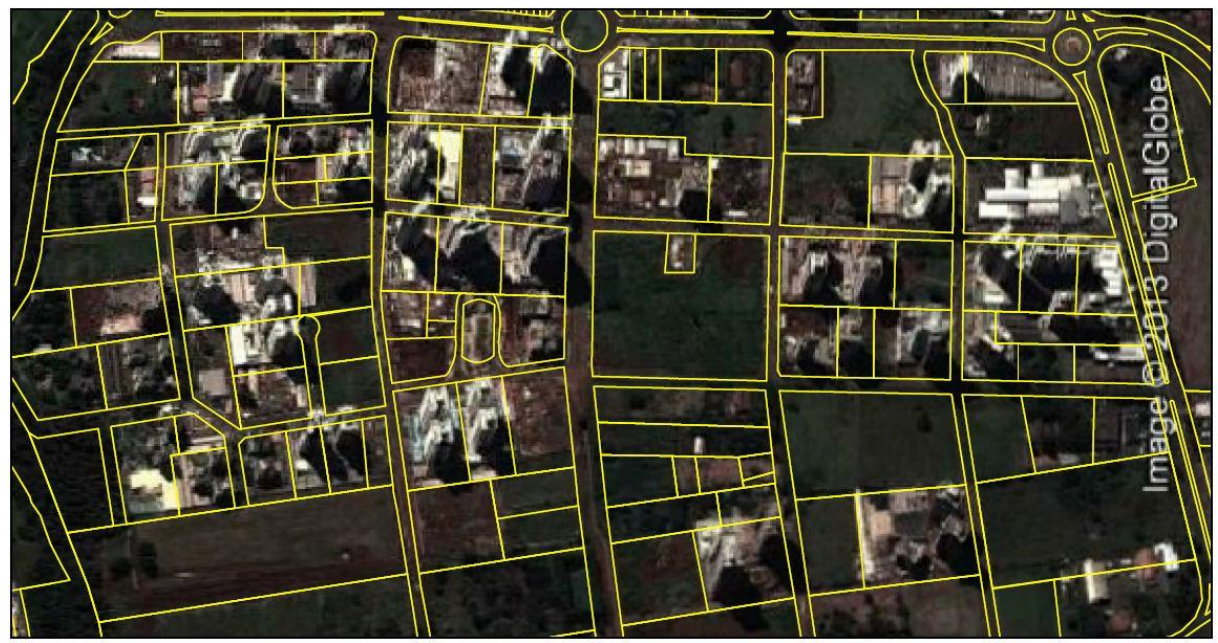

Figura 3: Sobreposição de imagens de 2013.

A quantificação das áreas (lotes) da região em estudo, com diferentes usos e ocupação do solo e nos períodos analisados, foi obtida a partir da utilização das imagens sobrepostas de 1991 e 2013, elaboradas pela autora. O valor de CN foi obtido através das tabelas de utilização e cobertura do solo do modelo do SCS, que são determinados com base na análise das características do solo, do uso e ocupação do solo em diferentes épocas e umidade antecedente.

Para que fosse possível esta quantificação (estimativa), foi elaborada uma paleta de cores para facilitar a representação das diferentes condições de uso e ocupação do solo, com base na tabela original. Esta pode ser observada na Figura 4, onde para cada tipo de utilização e cobertura do solo é estabelecida uma cor, que são contrastantes entre si.

Nas Figuras 5 e 6 são apresentadas as imagens que representam as estimativas das áreas dos lotes para as diferentes situações de uso e ocupação do solo na área em estudo para os anos de 1991 e 2013, nesta ordem.

Conforme descrito por Cavalcante et al. (2007), em estudo realizado no Campo Experimental de Engenharia Geotécnica da Universidade Estadual de Londrina (CEEG/UEL), o solo superficial da região se caracteriza por uma argila siltosa, de consistência mole à média, laterítica e colapsível, sendo conhecido como "terra roxa". Desta 
forma, o grupo de solo da classificação feita pelo SCS que mais se adequa a esta região, de acordo com as características geológicas, é o grupo C, uma vez que o solo local tem alta porcentagem de argila e com profundidade variável da camada. A condição média de umidade antecedente do solo foi considerada como condição II, que corresponde à umidade da capacidade de campo.

$\mathrm{O}$ valor final de $\mathrm{CN}$ foi obtido a partir da multiplicação da porcentagem de área para cada tipo de utilização do solo por seu respectivo valor de $\mathrm{CN}$ (atribuído pelo grupo do solo para bacias urbanas, proposto pelo modelo SCS) e pôr fim a somatória destes valores (ou seja, a média ponderada). Foram obtidos, respectivamente, valores de $\mathrm{CN}$ igual a 79,91 e 84,99, para as condições anteriores e posteriores à urbanização.

A partir das plantas topográficas e das imagens aerofotogramétricas foi possível obter a área total da região em análise $-674.153 \mathrm{~m}^{2}$ ou $0,67 \mathrm{~km}^{2}$, a extensão do trecho $1.100 \mathrm{~m}$, a declividade média do terreno $-14,67 \%$ e o número de curva $(\mathrm{CN})$ dos diferentes anos estudados (1991 e 2013) que foram obtidos através da quantificação das áreas com diferentes usos e ocupação do solo, realizada de forma visual.

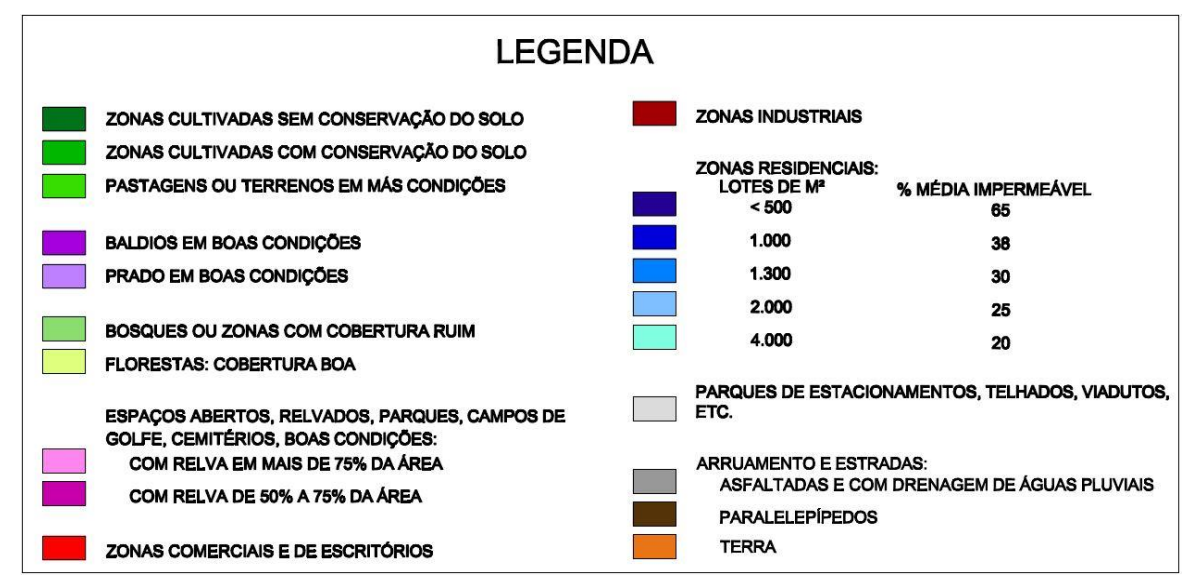

Figura 4: Paleta de cores utilizada para quantificação das áreas.

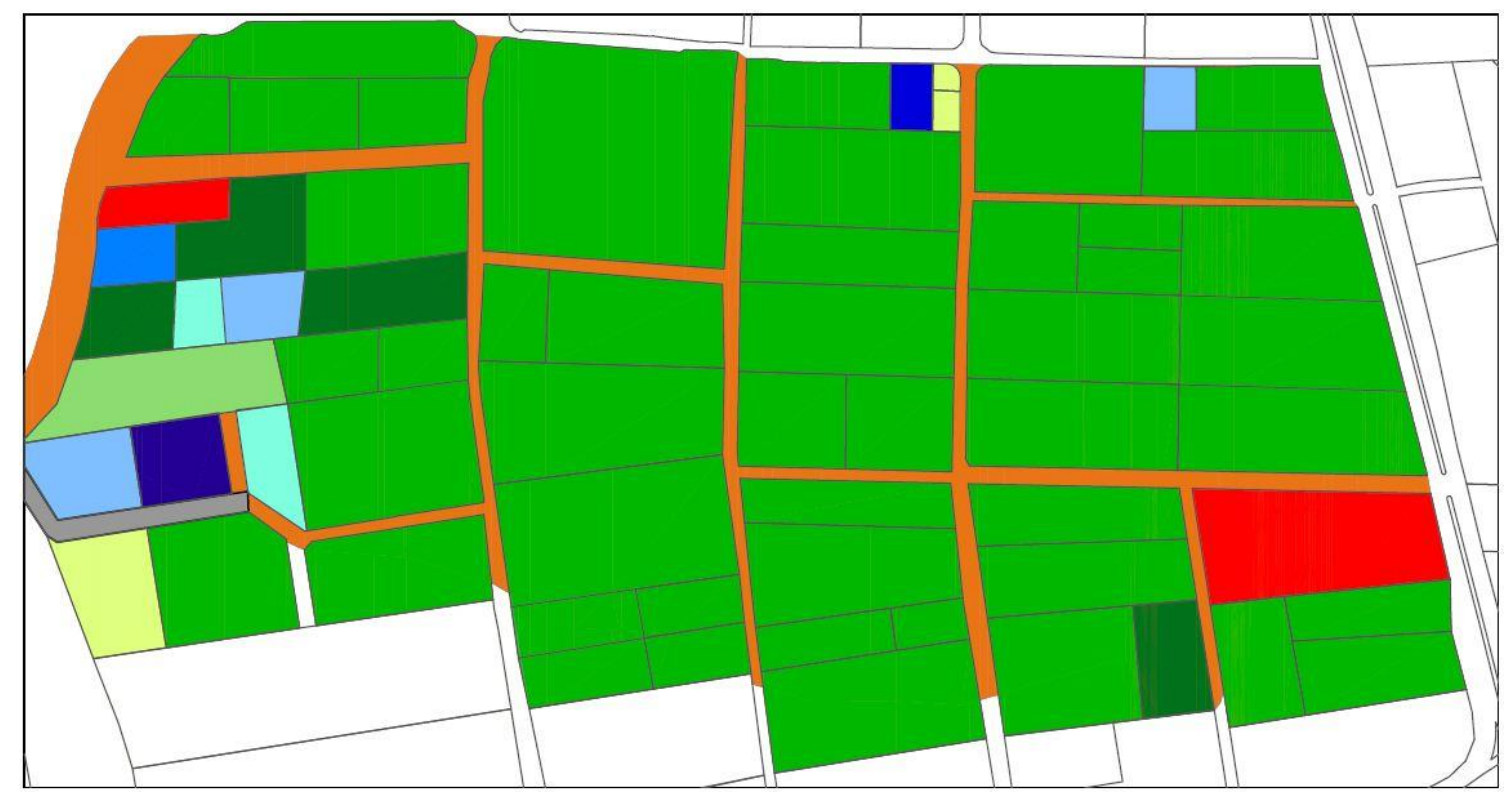

Figura 5: Representação das áreas com diferentes usos e ocupação em 1991. 


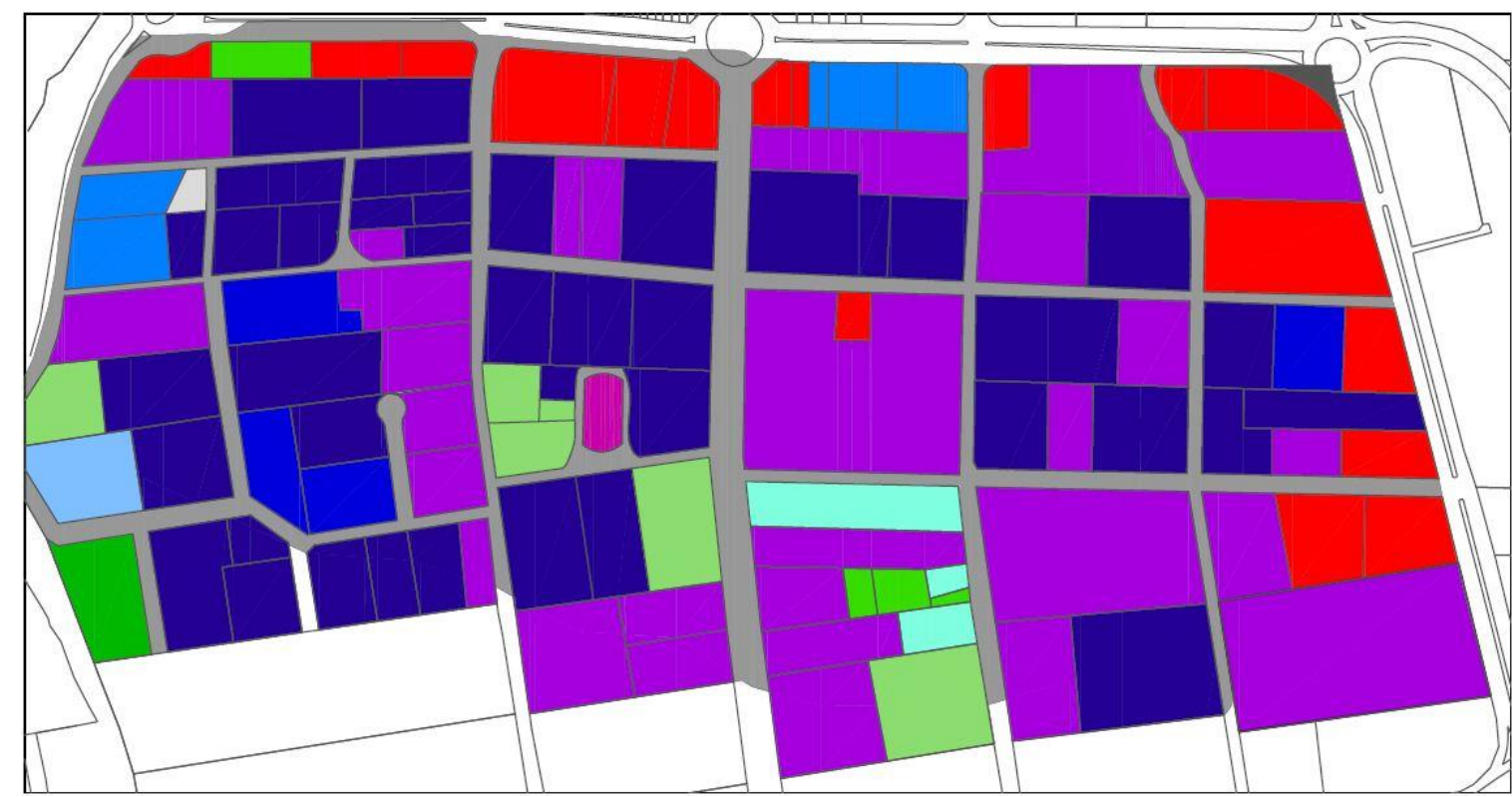

Figura 6: Representação das áreas com diferentes usos e ocupação em 2013.

\section{Resultados e discussão}

A seguir são apresentados os hietogramas e os hidrogramas obtidos nas simulações realizadas para os dois períodos analisados, um anterior a urbanização (1991) e outro posterior (2013). O solo da região de Londrina (PR) melhor se enquadra no grupo " $C$ " da classificação de solos do SCS.

O hietograma independe das condições da bacia e do uso e ocupação do solo, pois dependem apenas das condições da chuva propriamente dita. Portanto, os hietogramas, para cada condição da chuva são iguais para os dois períodos analisados. Os hietogramas de projeto mostram que quanto maior for o tempo de duração da chuva, maior será o pico de precipitação, que devido ao método utilizado para a obtenção dos hietogramas (Método dos Blocos Alternados), este sempre ocorrerá na metade do tempo de duração da chuva.

Em estudo realizado por Santos Junior (2012) sobre a análise estatística das precipitações ocorridas em Londrina/PR referente ao período de 1976 e 2011 não foi constatado mudanças significativas nas precipitações totais anuais e máximas diárias. Também não há indicação da existência de tendências (aumento ou decréscimo) nas séries históricas analisadas segundo os testes de Spearman e Mann-Kendall realizados. Ainda assim, é sugerido um estudo semelhante com chuvas de curta duração (10, 15, 30 e 60 minutos), uma vez que estas podem ter sofrido alterações na intesidade ao longo do tempo.

Verificou-se que nos hidrogramas resultantes gerados na planilha eletrônica, ocorreu um aumento significativo do volume escoado superficialmente. Os hidrogramas foram obtidos através de precipitações efetivas que foram adquiridas a partir dos hietogramas de projeto gerados para os respectivos tempos de retorno e tempo de duração das chuvas, e das caracterísicas do solo e das condições de uso e ocupação do solo, como demonstram os gráficos da Figura 7. 

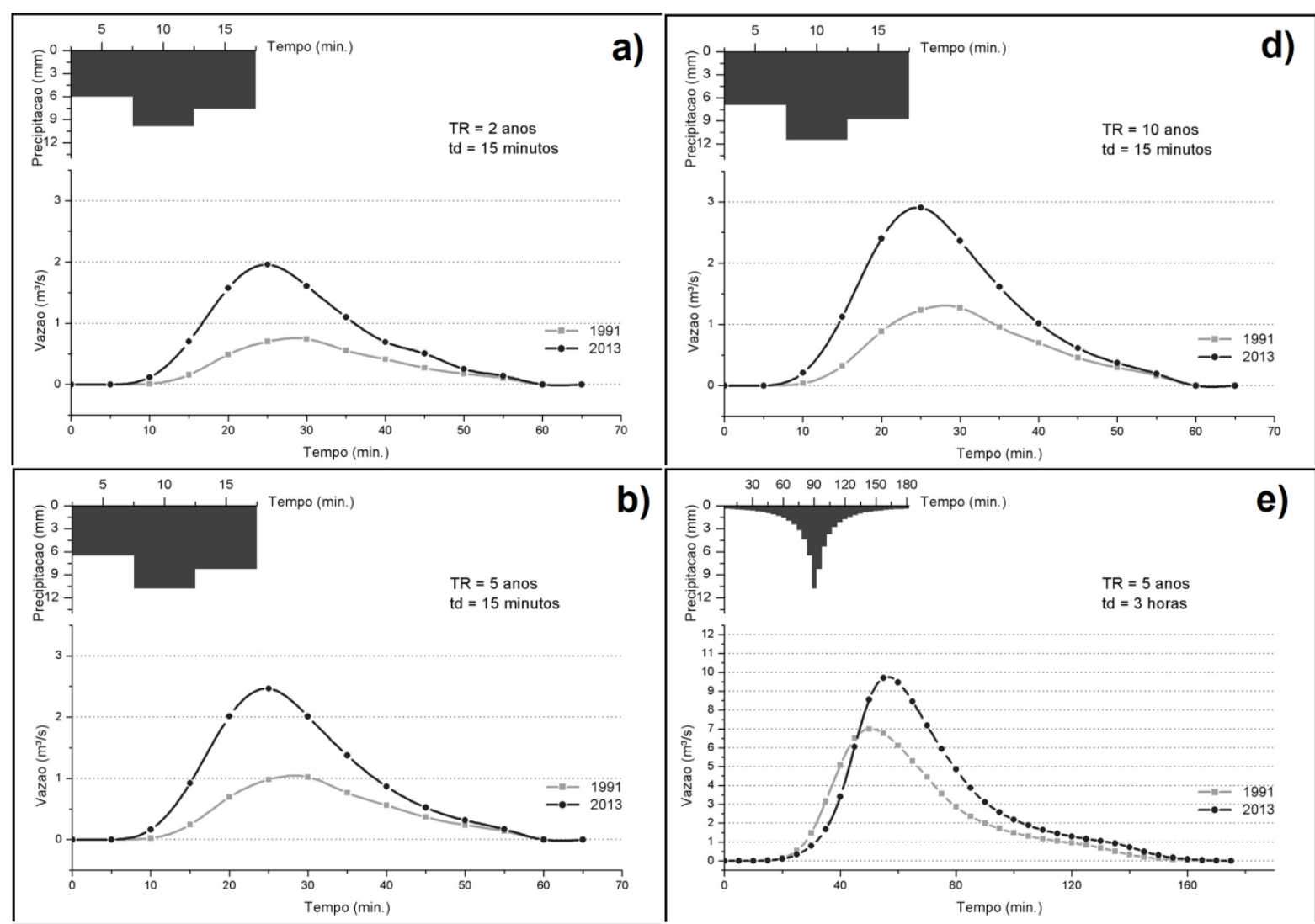

b)
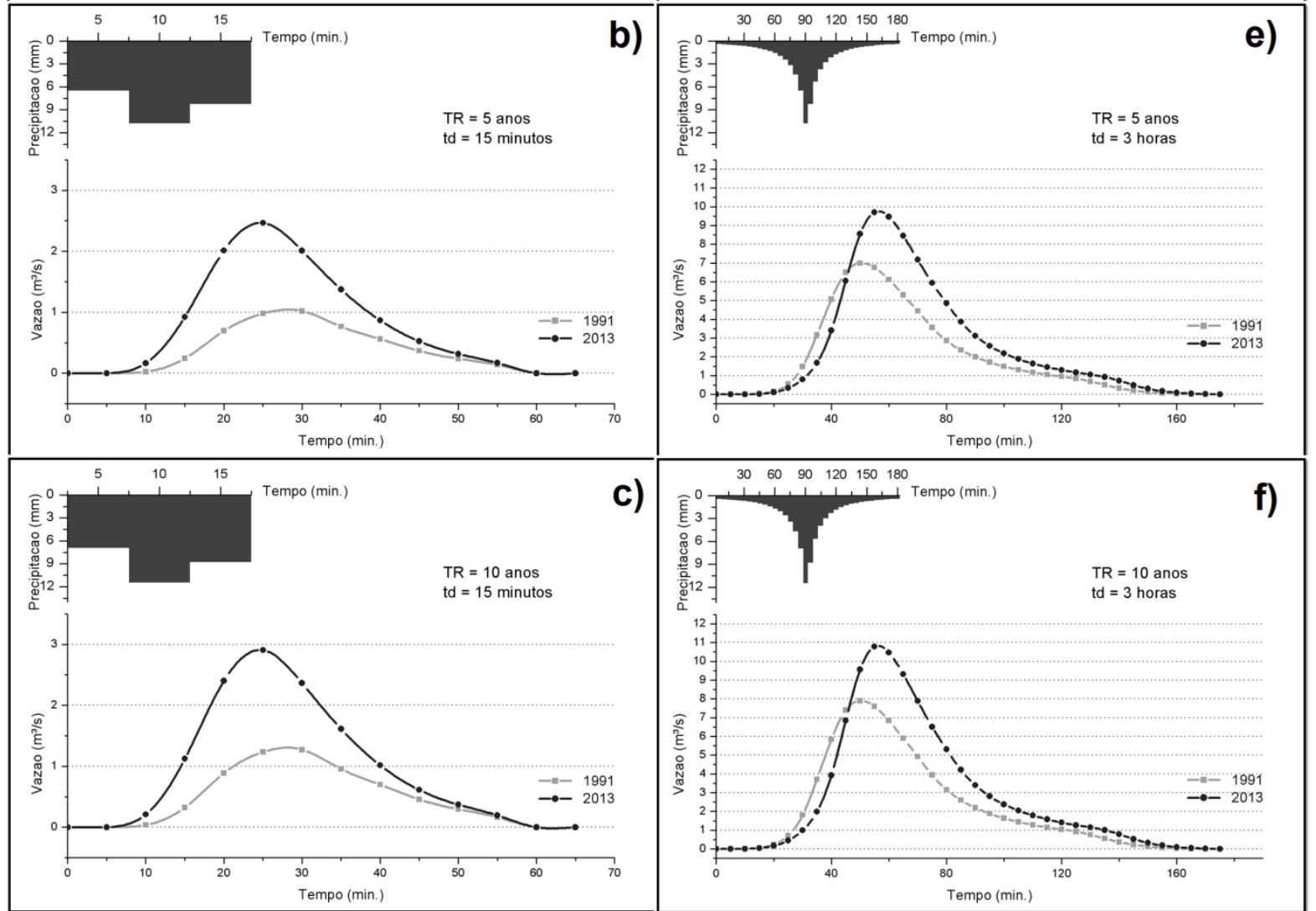

c)

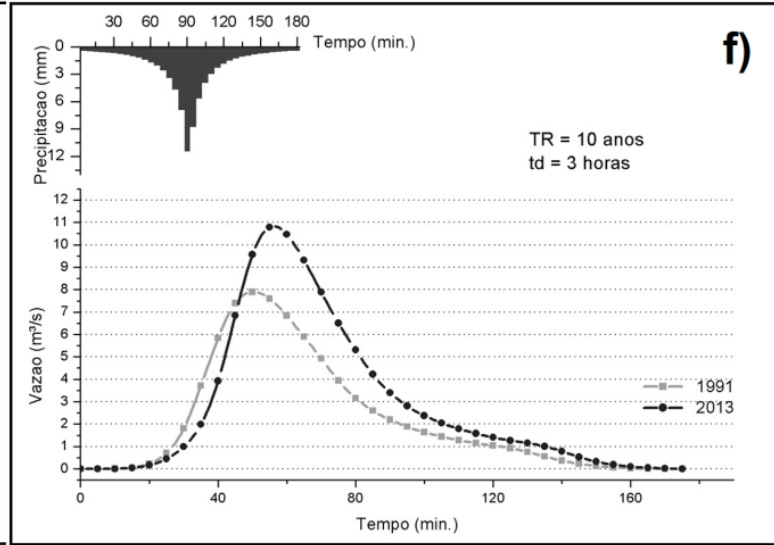

Figura 7: Hietograma e hidrograma para: a) $\mathrm{TR}=2$ anos e $\mathrm{td}=15$ minutos; b) $\mathrm{TR}=5$ anos e $\mathrm{td}=15$ minutos; $\mathrm{c}) \mathrm{TR}=10$ anos e $\mathrm{td}=15$ minutos; $\mathrm{d}$ ) $\mathrm{TR}=2$ anos e $\mathrm{td}=3$ horas; e) $\mathrm{TR}=5$ anos e $\mathrm{td}=3$ horas; $\mathrm{f}$ ) $\mathrm{TR}=10$ anos e $\mathrm{td}=3$ horas.

O volume escoado superficialmente foi obtido a partir da área do gráfico sob a curva (ou somatória das vazões) e a multiplicação desta pelo tempo do intervalo em segundos (5 minutos ou 600 segundos). Já a lâmina d'água foi obtida através da divisão do volume escoado pela área da região analisada. O tempo do pico e o valor da vazão foram adquiridos através da análise dos gráficos.

Na Tabela 1 pode ser observada uma síntese dos resultados, onde são apresentados os aumentos percentuais do volume escoado, vazão de pico e lâmina de água, comparando os cenários anterior e posterior a urbanização, para o tempos de retorno e de duração da chuva estudados. No gráfico da Figura 8 são mostrados os aumentos percentuais de volume em função do tempo de retorno e de duração das chuvas. 
Desta forma, foi verificado que para uma área de drenagem de $0,67 \mathrm{~km}^{2}$ e com as condições de uso e ocupação do solo em 1991 e 2013, o volume escoado superficialmente para tempo de retorno de 2 anos aumentou 139\%, 68\%, 44\% e 35\%, respectivamente para os tempos de duração de 15 minutos, 30 minutos, 1 hora e 3 horas. No caso de tempo de retorno igual a 5 anos, o aumento foi de $115 \%, 61 \%, 41 \%$ e $32 \%$, respectivamente, e para tempo de retorno de 10 anos, foi de $102 \%, 57 \%$, 39\% e 30\%.

$\mathrm{O}$ aumento do volume escoado superficialmente tende a ser maior quanto menor for o tempo de duração da chuva (Figura 8). Este fato está diretamente relacionado ás consequências do uso e ocupação do solo, ou seja, a impermeabilização que reduz a infiltração. Quanto maior for o tempo de duração da chuva, maior será o tempo de escoamento superficial, sendo que este fator independe do tempo de retorno.

Observou-se também que o pico de vazão teve um acréscimo com o passar dos anos, sendo que para tempos de duração da precipitação menores o aumento percentual da vazão foi maior. O acréscimo do pico de vazão, da mesma forma que o aumento do volume escoado, está relacionado ao uso e ocupação do solo, porém, além da redução da infiltração, as alterações das características das superfícies, menores rugosidades em relação a o natural, favorecem o aumento da velocidade do escoamento.

A lâmina d'água, que é formada a partir do escoamento superficial, aumenta com o tempo de duração e retorno da chuva, além de ser altamente dependente do uso e ocupação do solo. Quanto maior for o CN, maior será a lâmina formada. O aumento percentual deste escoamento superficial é mais visível quanto menor for o tempo de duração da chuva.

\begin{tabular}{|c|c|c|c|c|c|}
\hline & & & & & \\
\hline & & & 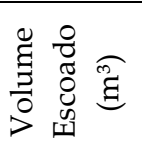 & 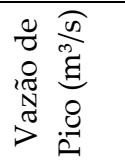 & 胥 \\
\hline \multirow{9}{*}{ 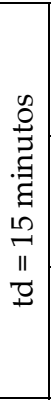 } & \multirow{3}{*}{$\operatorname{Tr}=2$ anos } & 1991 & 1.086 & 0,74 & 1,61 \\
\hline & & 2013 & 2.594 & 1,96 & 3,85 \\
\hline & & Aumento (\%) & 139 & 165 & 139 \\
\hline & \multirow{3}{*}{$\operatorname{Tr}=5$ anos } & 1991 & 1.511 & 1,02 & 2,24 \\
\hline & & 2013 & 3.248 & 2,46 & 4,82 \\
\hline & & Aumento (\%) & 115 & 141 & 115 \\
\hline & \multirow{3}{*}{$\operatorname{Tr}=10$ anos } & 1991 & 1.898 & 1,27 & 2,82 \\
\hline & & 2013 & 3.844 & 2,91 & 5,70 \\
\hline & & Aumento (\%) & 102 & 129 & 102 \\
\hline \multirow{9}{*}{ 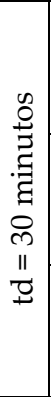 } & \multirow{3}{*}{$\operatorname{Tr}=2$ anos } & 1991 & 4.336 & 2,81 & 6,43 \\
\hline & & 2013 & 7.303 & 4,66 & 10,83 \\
\hline & & Aumento (\%) & 68 & 66 & 68 \\
\hline & \multirow{3}{*}{$\operatorname{Tr}=5$ anos } & 1991 & 5.421 & 3,23 & 8,04 \\
\hline & & 2013 & 8.752 & 5,54 & 12,98 \\
\hline & & Aumento (\%) & 61 & 72 & 61 \\
\hline & \multirow{3}{*}{$\operatorname{Tr}=10$ anos } & 1991 & 6.366 & 3,79 & 9,44 \\
\hline & & 2013 & 9.986 & 6,28 & 14,81 \\
\hline & & Aumento (\%) & 57 & 66 & 57 \\
\hline \multirow{6}{*}{ 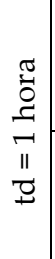 } & \multirow{3}{*}{$\operatorname{Tr}=2$ anos } & 1991 & 7.918 & 3,55 & 11,74 \\
\hline & & 2013 & 11.428 & 5,03 & 16,95 \\
\hline & & Aumento (\%) & 44 & 42 & 44 \\
\hline & \multirow{3}{*}{$\mathrm{Tr}=5$ anos } & 1991 & 9.392 & 4,17 & 13,93 \\
\hline & & 2013 & 13.276 & 5,77 & 19,69 \\
\hline & & Aumento (\%) & 41 & 38 & 41 \\
\hline
\end{tabular}




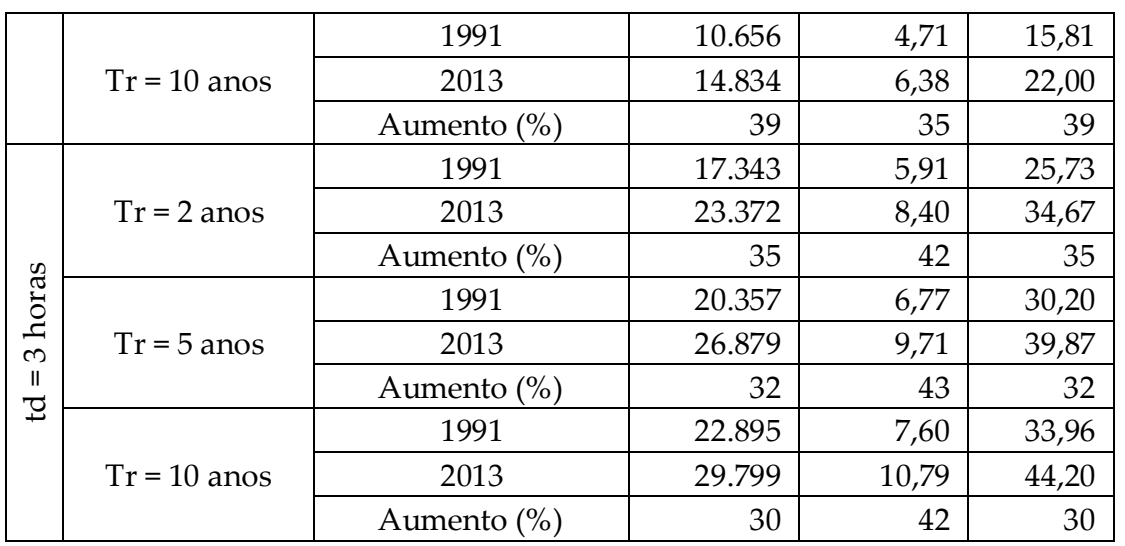

Tabela 1: Análise dos hidrogramas para td=15 minutos, 30 minutos, 1 hora e 3 horas.

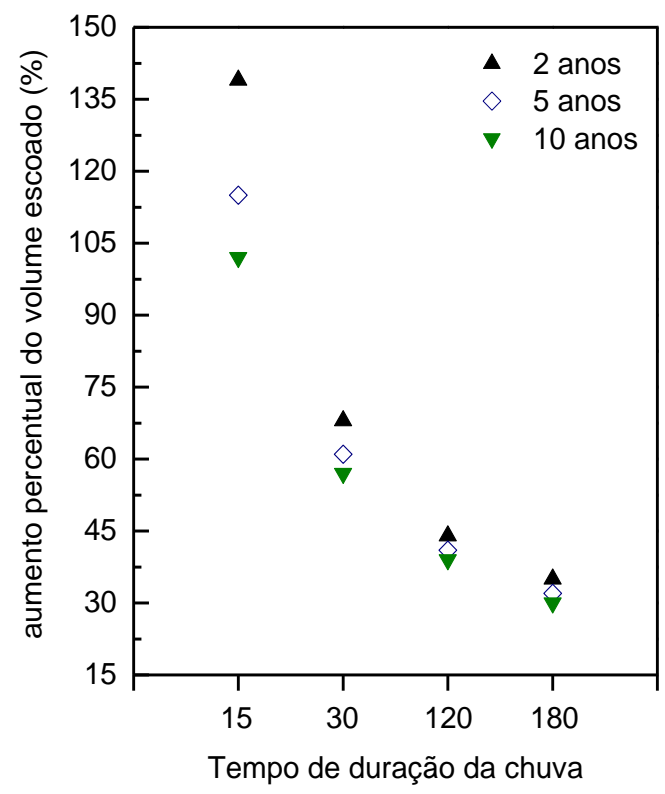

Figura 8: Gráfico de tendência de aumento do volume escoado superficialmente.

Estudos semelhantes como de Targa et al. (2012), também demostraram que o aumento da urbanização na bacia ocasionam a redução da infiltração potencial e que esta, por sua vez, faz com que haja o aumento do volume escoado superficialmente. Tal estudo foi realizado na bacia do igarapé do Tucunduba, em Belém do Pará.

Através da análise dos dados expostos anteriormente é possível perceber que para que haja a redução do volume escoado e/ou o amortecimento do pico de vazão é necessário a adoção de dispositivos de drenagem urbana sustentável, cujo objetivo é imitar o ciclo hidrológico natural. São exemplos destes: jardim de chuva, pavimento permeável e semipermeável, reservatório de detenção e retenção, trincheiras e poços de infiltração, telhado verde e faixa gramada (AGOSTINHO E POLETO, 2012).

Cada um destes dispositivos age de diferentes formas no controle do escoamento superficial, assim como possui limitações e cuidados específicos. Como descrito por Agostinho e Poleto (2012), o próprio sistema sustentável de drenagem urbana (SUDS Sustainable Urban Drainage System) possui aspectos positivos e negativos sobre sua utilização. 
Em contrapartida, Rezende, Miguez e Veról (2013) afirma que as soluções sustentáveis só são efetivas quando "num contexto amplo e reconhecendo as diversas interações entre as redes de infraestrutura urbana e o próprio desenho da cidade". Desta forma, segundo os mesmos autores, o planejamento do controle do uso e ocupação do solo é de grande importância para que o planejamento de controle de inundações seja efetivo e sustentável, sendo necessário também o desenvolvimento conjunto da malha urbana e do sistema de drenagem.

\section{Conclusão}

Verificou-se neste estudo que, para uma área de drenagem de $0,67 \mathrm{~km}^{2}$ e com as condições de uso e ocupação do solo em 1991 e 2013, para diferentes tempos de retorno e de duração houve aumento dos percentuais da lâmina d'água. Estes aumentos são mais perceptíveis quanto menores forem os tempos de retorno e tempo de duração das chuvas, variando de $139 \%$ para $\operatorname{Tr}=2$ anos e $t d=15$ minutos a $30 \%$ para $\operatorname{Tr}=10$ anos e $t d=3$ horas. Semelhante a isso, notou-se que as linhas de tendência dos aumentos são menores conforme os tempos de duração da precipitação aumentam.

\section{Referências bibliográficas}

AGOSTINHO, M. S. P.; POLETO, C. Sistemas sustentáveis de drenagem urbana: dispositivos. HOLOS Environment, v. 12, n. 2, p. 121-131, 2012.

BRUNO, L. O.; AMORIM, R. S. S.; SILVEIRA, A. Estudo da redução do escoamento superficial direto em superfícies permeáveis. Revista Brasileira de Recursos Hídricos, v. 18, n.2, p. 237-247, 2013.

CAVALCANTE, E. H.; DANZIGER, F. A. B.; GIACHETI, H. L.; SOUZA, A.; KORMANN, A. C. M.; BELINCANTA, A.; PINTO, C. S.; BRANCO, C. J. M. C.; CARVALHO, D.; FERREIRA, C. V.; MARINHO, F. A. M.; CINTRA, J. C. A.; DOURADO, K. C. A.; MORAES, L. S.; ALBUQUERQUE FILHO, L. H.; ALMEIDA, M. S. S.; GUTIERREZ, N. H. M.; ALBUQUERQUE, P. J. R.; CHAMEKI, P. R.; CUNHA, R. P.; TEIXEIRA, R. S.; MENEZES, S. M.. Campos Experimentais Brasileiros. Geotecnia (Lisboa), v. 111, p. 99-205, 2007.

FARIA, N. O.; BARBASSA, A. P.; SILVEIRA, A. Monitoramento, modelagem e simulação de cenários para a Bacia do Córrego Barbado - Cuiabá/MT. Revista Brasileira de Recursos Hídricos. v. 19, n. 1, p. 165-176, 2014.

FENDRICH, Roberto. Chuvas intensas para obras de drenagem no Estado do Paraná. Curitiba: Editora Universitária Champagnat, 1998. 99p.

INSTITUTO BRASILEIRO DE GEOGRAFIA ESTATÍSTICA (IBGE). Cidades@, Paraná, Londrina. Disponível em: <http://cidades.ibge.gov.br/xtras/perfil.php?codmun=411370>. Acesso em: 29 out. 2014. 
PREFEITURA DE LONDRINA. Dados Populacionais. Disponível em: $<$ http://www.londrina.pr.gov.br/index.php?option=com content\&view=article\&id=163\&Ite

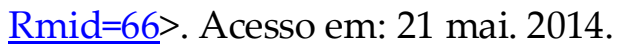

REIS, R. P. A.; ILHA, M. S. de O. Comparação de desempenho hidrológico de sistemas de infiltração de água de chuva: poço de infiltração e jardim de chuva. Ambiente Construído, v. 14, n. 2, p. 79-90, 2014.

REZENDE, O. M.; MIGUEZ, M. G.; VERÓL, A. P. Manejo de águas urbanas e sua relação com o desenvolvimento urbano em bases sustentáveis integradas - Estudo de caso dos Rios Pilar-Calombé, em Duque de Caxias/RJ. Revista Brasileira de Recursos Hídricos, v. 18, n.2, p. 149-163, 2013.

SILVA, G. B. L.; MOURA, T. A. M.; KOIDE, S.; CAMPANA, N. A. Influência de aspectos construtivos e de uso na eficiência de revestimentos com superfícies permeáveis. Revista Brasileira de Recursos Hídricos, v. 14, n.1, p. 123-134, 2009.

SOIL CONSERVATION SERVICE (SCS). 1985. National engineering handbook. Section 4Hydrology. Washington, DC.

TARGA, M. S.; BATISTA, G. T.; DINIZ, H. D.; DIAS, N. W.; MATOS, F. C. Urbanização e escoamento superficial na bacia hidrográfica do Igarapé Tucunduba, Belém, PA, Brasil. Ambi-Agua, Taubaté, v. 7, n. 2, p. 120-142, 2012.

TUCCI, Carlos E. M. Escoamento Superficial. In: TUCCI, Carlos E. M. (org.) Hidrologia: ciência e aplicação. . 4 ed. Porto Alegre: Editora da UFRGS/ABRH, 2009. (Coleção ABRH de Recursos Hídricos; v.4). p. 391-441. 